\title{
Effects of monoculture and polyculture practices in oil palm smallholdings on tropical farmland birds
}

\begin{abstract}
Industrial oil palm expansion has led to dramatic landscape changes that have negatively affected forest biodiversity in the tropics. In contrast to large-scale plantations, oil palm smallholdings may support greater levels of biodiversity through the implementation of multi-cropping system or polyculture. We examined bird species richness, together with community structure, conservation status, and feeding guild of existing smallholdings in Peninsular Malaysia. Based on point transect sampling, we sampled birds in 100 smallholdings that practiced either monoculture or polyculture farming. Our results revealed that bird species richness was significantly greater in monoculture smallholdings than in polyculture smallholdings, but the opposite was true for bird abundance. Non-forest birds constituted the major species of bird communities in oil palm smallholdings. However, we found that the abundances of insectivores and frugivores were greater in polyculture smallholdings than in monoculture smallholdings. In the monoculture models, predictor variables explained $11.31-19.98 \%$ of the variation in bird species richness. When polyculture was being practiced, bird species richness increased significantly with the height of ground vegetation cover, distance to major roads, and distance to rice fields. In the polyculture models, predictor variables accounted for $11.71-24.85 \%$ of the variation in bird species richness. We also found that bird species richness increased significantly with height of ground vegetation, but it decreased with ground vegetation cover and distance to rivers. The evidence from this study suggests that monoculture and polyculture farming were able to maintain farmland biodiversity in smallholdings, at least for birds, but differed in richness, population, and feeding guild.
\end{abstract}

Keyword: Agriculture; Oil palm; Biodiversity; Bird species richness; Conservation; Feeding guild 